Institutioning: Participatory Design, Co-Design and the public realm Peer-reviewed author version

HUYBRECHTS, Liesbeth; Benesch, Henric \& Geib, Jon (2017) Institutioning:

Participatory Design, Co-Design and the public realm. In: CoDesign (Print), 13(3), p. 148-159.

DOI: $10.1080 / 15710882.2017 .1355006$

Handle: http://hdl.handle.net/1942/24400 


\title{
Institutioning: Participatory Design, Co-Design, and the Public Realm
}

\author{
Liesbeth Huybrechts
}

Arck, Hasselt University, Hasselt, Belgium

Campus Diepenbeek, Agoralaan Gebouw E, BE 3590 Diepenbeek Belgium, 0032112921

01, liesbeth.huybrechts@uhasselt.be (corresponding author)

Henric Benesch

HDK - Academy of Design and Crafts, University of Gothenburg, Sweden

Kristinelundsgatan 6-8, SE 40530 Göteborg, 0046766181858, henric.benesch@hdk.gu.se

Jon Geib

Architecture and Civil Engineering, Chalmers University, Sweden

Chalmersplatsen 4, Gothenburg, 004631772 1000, jonathan.geib@chalmers.se 


\section{Institutioning: Participatory Design, Co-Design, and the Public Realm}

In this introductory article to the special issue 'Co-Design and the Public Realm', we discuss a common interest in how meso- and macro-political institutional contexts frame and are informed by Participatory Design (PD) and Co-Design processes. We argue that unilateral focus within PD and Co-Design on the micro-political scale of fieldwork obscures interactivity with institutional framing processes, undermining their potential as sites of critique and political change. Our argument is drawn from a study of literature on the role of institutions in relation to PD and the public realm and our experience as participants in an EU-funded research project. The case study descriptions unpack how various institutional frames inform PD processes and how, conversely, PD processes inform various institutional frames: metacultural frames, institutional action frames, and policy frames. To highlight the move to engaging with and creating new institutions, we introduce the notion of institutioning.

Keywords: Co-Design, Participatory Design, institutioning, public realm, politics

\section{Introduction}

In Ruling the Void: The Hollowing of Western Democracy, Mair (2013) portrays a postpolitical landscape of blurred and eradicated lines between public and private spheres, driven by a rapidly expanding gap between party democracy (and its ruling class) and the wider society. An era of participation and intensified dialogue and exchange between societal and political institutions and society as such is both called for and called into question. In relation to these developments, the articles in this special issue detect an expanded interest and field of operations for Participatory Design (PD) and Co-Design, particularly in relation to the public realm. This introductory article unpacks this engagement by interrogating the institutional (meso- and macro-political) frames that inform and are informed by micro-level PD and Co-Design processes acting at the intersection of academia, the public/private sector[s], and (public) space.

This discussion is closely related to the question of how the historically political character of Participatory Design (PD) and Co-Design manifests itself today (Teli 2015; Kyng 2015). The tradition of Scandinavian PD that developed in the 1970s shared concerns and values with labour unions in emancipating workers at the workplace (Bannon and Ehn 2012, 39). Co-Design is also closely intertwined with a political project of questioning and 
reconfiguring power relations and notions of expertise (Lenskjold et al. 2015). In the 1970s, this political and activist engagement with the public realm was closely associated with publicly visible structures and institutions undergoing processes of automatisation: city hall, unions, and private companies.

However, in the Post-Fordist era, the public realm, and PD's and Co-Design's engagement with it, have been transformed in interaction with increasing globalisation, flexibility, rapid technological developments, a highly diverse and competitive market, and changing social conditions (Boudry et al. 2003, 43). Many traditional aspects of the public domain, such as mobility or communication infrastructure, were privatised, resulting in progressively more complex relations with governance and regulation (Graham and Marvin 1994; Christopherson 1994). In short, in a Post-Fordist context, designing takes place across previously delineated and contrasting spheres (or economic sectors, city borders, sociopolitical collectives, and discourses), such as public/private, work/leisure, local/global— the boundaries between which become increasingly blurred.

Mouffe (2013) argues that these conditions have lead in the field of art (artists, curators etc.) to further withdrawal from engagement with institutions, as perception of the all-pervasiveness of commodification under neoliberalism is intensified. One way this manifests itself is in the art field's - which can also be found in the field of design - disdain for 'traditional', 'monolithic' institutions and insistence on 'non-representative forms' of democracy based on self-organisation (66). Engagement with unions and political parties (as outlined by Mair 2011) is avoided. This is closely related to ascendant participatory culture, where more promise is placed in the hands of citizens themselves (Jenkins 2006). This rationale, which holds that participation can potentially take place anywhere with anyone, presents another reason PD designers have partly exchanged their strong relations with traditional public institutions in the city (Lenskjold et al. 2015) and private companies (Blomberg et al. 1993) for smaller citizen-initiatives or professional entities (DiSalvo et al. 2012). While the diversity of relations that PD and Co-Design develop with their environments is interesting, it brings new challenges. Public and private entities engaged in participatory work outside of institutional contexts can unintentionally support neoliberal ideals of individualisation and de-politicisation (e.g. in the field of care, Kyng 2015), while the smaller scale of the entities involved in contemporary PD and Co-Design requires new ways of working to generate enduring effects on the public realm. These challenges have revived the discussion on the political ambitions of PD and Co-Design. 
In this introductory article we want to further explore an issue raised by several authors in this special issue, 'Co-Design and the Public Realm': namely, that instead of ignoring and downplaying institutional frameworks, a re-engagement with institutions is necessary if we are to re-politicise PD and Co-Design. To make this argument, we build on Mouffe's (2013) plea for engaging with institutions in agonistic ways, where consensus can be challenged and new modes of identification made available. Our argument is strengthened by Streeck and Thelen's (2005) theorisation of formal institutions as highly dynamic and contested spaces where change is not only imposed from the outside but also generated from within. This revitalised engagement with institutions may not only strengthen PD and CoDesign as practiced outside these institutions in civic society, but may also contribute to a revitalisation of work inside institutions: their framing as institutions as such, as well as to the re-articulation of existing institutional frames. We introduce the term institutioning in order to promote the movements being made within these fields to re-engage with institutions and find new relations within the complexity of the contemporary public realm.

\section{The political nature of PD and Co-Design}

The term community-based PD is frequently used to refer to PD's and Co-Design's political role in giving form to the public realm in democratic ways, engaging existing 'publics' and making new ones around issues at stake (e.g. ecology, poverty) on a city level (DiSalvo and Pipek 2012; Le Dantec and DiSalvo 2013). In the same way, the term infrastructuring is used by Björgvinsson et al. (2010) to refer to PD's and Co-Design's development of relations and resources which aim to enable the possibility for change to come about and be self-sustained. These relations and resources can conversely be inscribed in particular political topographies, safeguarded by various social, cultural and economic institutional frameworks. While the concepts of community-based PD and infrastructuring have contributed greatly to our understanding of how to engage with the public realm, the fact that PD and Co-Design researchers have meso- and macro-political responsibilities and alliances on an institutional level, for instance as state funded employees, tends to be at the margins of discussions. There is a great focus on a micro-political scale: the immediacy of work in the field with communities. Over-focus on this micro-political scale can obscure the collective aspect of politics defined as processes of dissensual reconfiguration — or reframing of - 'common sense' (Rancière 2004, 25; Mouffe 1993), specifically by neglecting the inseparable 
processes which reinforce frames of 'common sense', processes Rancière terms 'the police' (Rancière 2010, 53).

PD's and Co-Design's move into the city was intended as a political act. However, in its focus on the micro-political scale, it has paradoxically contributed (indirectly) to depoliticisation by inhibiting researchers from zooming out and seeing the complexity of the blurring boundaries in which their design activities take place. We are not arguing that PD researchers stop doing important micro-political work, but rather for a more critical acknowledgement of the ways in which PD processes are inscribed in, and dependent on, institutional actors.

\section{PD, Co-Design and institutions}

Following Helmke and Levitsky (2003) we differentiate between formal institutions, such as courts, hospitals, universities, municipalities, and so on, and more informal institutions relating to civic, religious, kinship, and other socially shared rules - usually unwritten - that are created, communicated, and enforced outside of official channels. PD and Co-Design have strong formal and informal institutional roots. They have developed within researchoriented frameworks and funding structures, but also in direct engagement with other types of institutions, such as unions in the Nordic context. The aforementioned post-Fordist blur produces combined processes which often include various institutions such as municipalities (as hosts or recipients), universities (involving students and researchers), development and/or research councils, and private companies (providing funds and setting policies). PD's and Co-Design's entanglement with various institutions dealing with research, education, welfare, and urban development — just to name a few — has thus grown more intense and complex.

While we often consider our work as PD and Co-Design researchers as being 'on the ground' where citizens are involved, the work that makes this happen extends far beyond this: it requires legislation-checks, policy-checks, fund-raising, partnership-forming, reporting, and assessments in relation to all parties involved. It is not unusual in PD and CoDesign practices that these institutional entanglements are not mentioned to citizens in order not to scare them away. Likewise, academics tend to exclude 'back office' institutional engagements from papers so as not to overload them. Dindler and Iversen (2014) argue that these relations, always part of PD processes, are important but usually remain implicit. We argue that this tendency not to address - either 'on the ground' or in a research context - the institutional frames within which PD and Co-Design processes are set-up adds further to their 
de-politicisation, since they become seen as an outgrowth of policy rather than as sites of real political possibility. Further, such detachment from institutional context feeds the conventional understanding of institutions as inert entities and produces situations, again as noted by Mouffe (2013), wherein people feel change can only happen outside of institutions, thus ignoring institutions as political platforms and sites of change.

By introducing the term institutioning, we want to draw attention to institutions as active sites of change which play a role in framing PD and Co-Design processes, rather than existing as inert backdrops. These framings are not merely to be understood on a legislative and policy level but also on an epistemological level by how they reconfigure the 'distribution of the sensible' (Rancière 2004). Castell (2016) building his argument on Schön and Rein (1994) outlines a notion of 'institutional framing' that distinguishes between: broader societal 'meta-cultural frames' such as democracy, sustainability, and citizenship; 'institutional action frames' such as participation and dialogue; and 'policy frames' such as guidelines, agreements, and policy documents. Further, a wide range of international, national, regional, municipal, and local institutions with various social, economic, and educational scopes and mandates are at play in most cases, providing support (financial) as well as guidelines (policy). In literature, three ways of dealing with these frames are addressed:

1. There is a body of literature through which we can understand institutioning as comprised of gradual processes of altering (consolidating or challenging) existing frames of institutions. We can find this in Mahoney and Thelen's (2009) study of gradual institutional change, in which institutions are understood as fundamentally dynamic (albeit often slowly evolving) entities where 'important changes often take place incrementally and through seemingly small adjustments that can, however, cumulate into significant institutional transformation' (xi).

2. Other authors have stressed how institutional frames are complemented and challenged by other frames. Ahrensbacj and Buenderman $(2012,89)$ discuss the potential of what they call 'the civic economy', or citizens who organise themselves in new types of associations including collectives and commons. They challenge existing frames by articulating the need for policy makers, designers, and large economical players to admit a wider range of actors and tap into local capabilities and opportunities. Ampatzidou et al. $(2015,70)$ also stress that, in city-making, the modes of producing frames by individual citizens and collectives of citizens need to be considered alongside institutional framing processes. 
3. Within PD, much reflection takes place on how to give 'form' to new institutional frames that can support the growth of civic initiatives. Teli (2014) argues that designers should find allies in the 'Fifth Estate': highly-skilled citizens who are often drivers behind civic initiatives such as co-working spaces. Kyng (2015) speaks about the need to build a 'middle element' which can support the sustainability of smallscale projects and initiatives that have grown from collaborations between designers and (collectives of) citizens. He suggests a need to set up new-maybe even permanent - organisations or institutes which can sustain the results of participation.

\section{The case study: TRADERS}

We now turn to a case study to analyse the notion of institutioning by drawing on our experience between 2012 to 2017 as two senior researchers and one PhD student in an EUfunded research project, TRADERS, or 'Training Art and Design Researchers in Participation for Public Space'. Our analysis is based on qualitative clustering of research data generated by the project as a whole and by three of its six subprojects - so called Work Packages (WPs). The research data consists of the funding proposals, policy documents, communications, documentation from research activities, research papers, and exhibition material created during the course of the project. Our ambition is to unpack how the core concepts and the three ways of dealing with institutional frames foregrounded by literature played out in relation to this particular project.

The process which brought TRADERS into being started in 2012 when the Faculty of Arts of the University of Leuven began efforts to intensify exchange between countries in order to increase the quality of its $\mathrm{PhD}$ programs. One of the strategies was to develop a new program for a topic in which two large groups within the faculty had expertise, namely participation in public space. The local team engaged strategic international partners that the faculty already had exchanges with on a PhD level, Chalmers University of Technology (Chalmers) and the University of Gothenburg (UGOT), both situated in Gothenburg, and two partners that it had developed partnerships with on a project level, Design Academy Eindhoven and the Royal College of Arts. This consortium decided to apply together for an FP7, Marie Curie Multi-ITN (Initial Training Network) project application. This significantly impacted how the institutional consortium was formed as it required the hiring, training and mobility of $\mathrm{PhD}$ researchers in between academic and non-academic public and private partners. In this way the art centre Z33 (BE), the playground supplier KOMPAN (DK), the 
City of Gothenburg (SE), the service design company STBY (NL) and the architecture firm Studio E (UK) became involved. The proposal was submitted in a social sciences track due to the absence of a specific track on art and design research. The consortium engaged the Architecture Department of the University of Leuven with expertise in a social scientific approach to participation and public space. It was decided that each partner explore one specific methodology in relation to participatory art and design research in public space ('multiple performative mapping', 'intervention', 'play', 'modelling in dialogue' and 'data mining') connected in a 'meta-framework' by the social scientific partner.

Supported by funding granted by the University of Leuven for initial meetings and proposal writing, the project was approved and a call was launched for six $\mathrm{PhD}$ positions for Early-Stage Researchers (ESRs). Through the funding, TRADERS became a virtual and contractual organisation coupled together in work packages with $\mathrm{PhD}$ positions/projects as the main component, hosted and supervised by the academic partners and seconded by the non-academic partners. Each researcher was selected based both on the profile of one partner organisation and the common project goals. Through the organisation and communication of activities by the different partners - an opening symposium, two summer schools, five training weeks, a final conference, a book publication, and this special issue, as well as a number of other dissemination activities such as workshops and conference presentationsTRADERS is positioned internationally within the fields of art and design research and professional practice. In the sections that follow, we will look into three of the work packages (WPs).

\subsection{Case 1: WP 'Intervention' - De Andere Markt}

The WP 'Intervention' was hosted in Belgium by the LUCA School of Arts (involving 4 research groups concerned with participatory design, art and public space) and seconded by the art centre Z33 and the Faculty of Architecture of the University of Hasselt. This WP stated that: 'Intervention in public space can be understood as a participatory act performed to stimulate (public) involvement in design research that aims to create social awareness regarding public issues.' To develop this, the academic consortium had the support of their hosted $\mathrm{PhD}$ researcher in setting up a case study, De Andere Markt, a Living Lab in the city of Genk. Because of a massive drop in job opportunities following the closing of local mines, and later the Ford factory, different city departments, the Flemish government, and certain international actors became interested in the Lab and its participatory models of 'designing 
for work'. As a result, the Lab attracted approximately 15 funded projects between 2014 and 2017 and secured an arrangement in which the city paid the rent of the Lab's venue, enabling the project to work with the local community over time. Through interventions the Lab aimed to involve local citizen and professional groups in longer-term engagements which give form to the future of work in their city.

The interventions were designed by the $\mathrm{PhD}$ researcher and assisted by a cargo bike extended with a printing press, which he created. Since the $\mathrm{PhD}$ researcher is not a native Dutch speaker, he was supported by his Dutch-speaking PhD supervisor and local $\mathrm{PhD}$ researchers, who together used the press to enter public space and invited people who are part of small-scale (e.g. community gardens) and large-scale initiatives (e.g. a food service company) to print their skills on a poster and speculate on how these skills can contribute to the future of work in their city. The posters were then collected in an online collage, now consisting of more than 150 citizen's skills. Protagonists in these narratives were gathered into Co-Design sessions to imagine alternative future ways of working together (e.g. through a new form of food cooperative). These alternatives were shared on the online platform and through exhibitions in the Lab.

\subsection{Case 2: WP 'Modelling in Dialogue' - Ett skepp kommer lastat...}

The WP 'Modelling in Dialogue' was hosted in Sweden by the Architecture Department of Chalmers University of Technology and seconded by the City of Gothenburg. This secondment partnership was pivotal in opening up a broad landscape of local actors, arenas, and programs within which the hosted $\mathrm{PhD}$ researcher's primary case study emerged and took shape in both a designed and contingent manner. His mapping of this landscape revealed that a sub-district cultural center's upcoming (2015) programming theme 'neighbours' resonated with his interest in exploring a cultural form of participation influenced by urban sociologies of difference and distance. The $\mathrm{PhD}$ researcher was invited to propose a project which later adopted the name Ett skepp kommer lastat..., after a Swedish children's game in which players take turns guessing the contents of a distant ship.

First envisioned were six workshops involving a group of local children (an afterschool group), the $\mathrm{PhD}$ researcher, local inhabitants and their built environment, and artifacts in alternating participatory modes and roles. The $\mathrm{PhD}$ researcher's need to work with a Swedish-speaking pedagogue led to a widened collaboration bringing in three new classes or 
'neighbours' by way of an existing city cultural program. Yet, this program and the teachers utilising it were so accustomed to single, standalone workshops that these workshops were reconceived and eventually reduced to two with each class, although this arrangement was still challenging. The $\mathrm{PhD}$ researcher then intensified the wider dynamics of differential involvement by integrating, through curriculum exercises, three more classes of youth from a local international school. The larger scope partly led to the project being offered a full exhibition in the cultural center which, in turn, precipitated another substantial reconfiguration of its timeline, content and constellation of workshops. The exhibition's carefully considered design and the quality of its contents challenged conventional ways of working with children and youth, making an impression on visiting officials from city- and regional-level cultural departments, many of whom perceived a new way of taking children and youth seriously.

\subsection{Case 3: WP 'Play' - Recipes for unControl}

The WP 'Play' was hosted in Sweden by the Academy of Design and Crafts (HDK) at the University of Gothenburg (UGOT) and seconded by Kompan and the City of Gothenburg. This WP addressed 'how public space can be re-conceptualised and materialised in view of the particular challenges and opportunities provided by children and young adults.' The WP profile was developed particularly in relation to one of HDK's MA programs, Child Culture Design (CCD), and the PhD program for Artistic Research established at UGOT's Faculty of Fine, Applied and Performing Arts. The WP also actualised an existing but dormant agreement between UGOT and the City of Gothenburg on progressive policy in relation to working with and for children. This was a factor in enabling the $\mathrm{PhD}$ researcher to initiate a project, Recipes for unControl, with Göteborgs Konsthall (Gothenburg Art Hall), one of the public institutions within the city's Cultural Department. The project became a part of the Konsthall's Tryckverkstaden (Print Workshop) project, and involved students from an elementary school—-The International School of the Gothenburg Region (ISGR) — who had also previously worked with the CCD program. The project also involved students from this program.

Through the medium of a workshop and an exhibition, the project explored how young adults today perceive borders in public space. Together, they created prints of subjective narratives and 'recipes' prescribing how to deal with these borders in a playful way. These prints and the project were then exhibited and presented in the Konsthall, 
demonstrating alternative ways in which art centres can work with children in public space, as well as new methods of research and education at the host institution (HDK).

\subsection{Observations}

The three WPs within the TRADERS case provide an empirical background illustrating how PD and Co-Design projects and processes are framed by a range of institutions. Although large EU programs such as this FP7, Marie Curie Multi-ITN can be regarded as extremes in their capacity to draw together local, national, and international actors across institutions, organisations, and sectors, we also see that many characteristics are shared with a growing number of PD and Co-Design projects performed within research and/or municipal contexts. Consequently, we discuss four tentative observations that we believe can provide insight to a broader context of PD and Co-Design projects.

(1) PD and Co-Design processes cannot be understood exclusively as projects on a microlevel as they are dependent on and informed by meso- and macro-level institutions and their policy frames, institutional action frames, and meta-cultural frames.

The hands-on activities presented in the WPs show that they are nested in, highly dependent on, and responsive to the various capacities, policies, regulations, agendas, and hosting parameters of institutions at international, national, regional, and local scales. In Case 1, for instance, the existing orientation of the city's policy frames and institutional action frames to 'work' enabled their support in setting up the Lab. Similarly, in Cases 2 and 3, policy frames and institutional action frames concerning children, culture, and education enabled the city's support and hosting of the PD activities described. In Case 2, the project's configuration changed dramatically as it navigated between various institutional levels, informed by associated policy frames (following Schön and Rein 1994). The cases also show how policy frames at the macro-level have a direct impact on micro-level PD and Co-Design activities. The cases' choices of context and approach, and their actualisation, were directly informed by the policy frames of the FP7 Marie Curie Multi-ITN Program, in which ESR candidates (the $\mathrm{PhD}$ students) are not eligible if they have lived in the country of the host institution in the three years prior to the project. In each case, PD activities on the ground take on multiple 'second lives' at conferences, for instance, as currency within various institutional economies dominated by different sets of policy frames, institutional action frames, and meta-cultural frames. And here, again the research methodologies, peer-review processes, and open access 
practices of the universities involved, for instance, shape the way these continuations are setup and performed.

(2) Recognition of the institutional dependency of PD and Co-Design projects and processes, in turn, enables recognition of the potential of these processes to effect direct and indirect institutional change in terms of policy frames, institutional action frames, and meta-cultural frames, primarily at the meso-level of the institutions involved.

PD and Co-Design projects inform a range of institutional frames. In all three cases, microlevel activities engendered a discussion on the institutional action frames of the institutions involved, which opened up for direct changes to policy frames as well as for longer-term shifts in meta-cultural frames. Dissemination activities were one way in which this took form. Projects like TRADERS become the empirical material for a range of 'by-products' such as papers, talks, articles, or panels, showcased within various conferences and seminars. These products become potential drivers of discourse and changes in policy frames, institutional action frames, and meta-cultural frames at the meso- and - in the long run - the macro-level. Partly because of these dissemination practices, institutions hosting the WPs discussed (LUCA, Chalmers and UGOT) and associated partner institutions (Z33 and the City of Gothenburg) have subsequently incorporated participation in such projects into their institutional action frames. This has also generated discussions on the meta-cultural frames of these institutions, particularly on the issue of becoming more internationalised.

(3) Institutioning, as an active component in PD and Co-Design processes, is multi-scalar, multi-directional, and requires constant vertical and horizontal movement between, and within, various micro-, meso-, and macro-levels.

The way PD and Co-Design projects are informed by, and inform, their institutional frames, as outlined in (1) and (2), ultimately points to institutioning as an active component, as an oscillating movement between and within institutional scales. All three cases illustrate how issues and projects migrate back and forth, vertically and horizontally, within the institutions and organisations involved: translation occurs between policy and on the ground activities which, conversely, translate into changes in policy frames, institutional action frames, and meta-cultural frames. Put differently, PD and Co-Design are a dynamic combination of topdown, bottom-up, and lateral movement. 
(4) Institutioning, in PD and Co-Design processes, calls attention to the significance and specificity of their relations with policy frames, institutional action frames, and meta-cultural frames, as these relations can be, to varying degrees, consolidative, challenging, and/or formative.

In each case, $\mathrm{PD}$ and Co-Design processes gained momentum through their alignment with various policy frames, for instance those pertaining to 'work' and 'children', thus consolidating these very frames. However, they may also challenge others, as they did in Cases 2 and 3 in relation to existing policy and institutional action frames. Case 1 exemplified a situation where PD and Co-Design processes can contribute to the formation of new institutions - in this case a micro-level food cooperative, which was enabled through alignment with various meso- and macro-level frames. The consolidative, challenging and formative aspects of institutioning thus also need to be understood as operating between and within micro-, meso-, and macro-levels.

\section{Institutioning in the public realm}

We explored challenges facing PD and Co-Design researchers engaging in the increasingly blurred public realm. The literature outlined in earlier sections identified the opportunities lost when PD and Co-Design withdraw from this wider complexity through unilateral focus on the micro-political scale. In order to emphasise and expand on the historically political character of PD and Co-Design processes, strongly based in institutional contexts, we use this concluding discussion to foreground institutioning as an inherent, but not necessarily explicit, component of these processes in the context of the Global North. We suggest that the capacity of PD and Co-Design processes to effect political change, and their resistance towards processes of instrumentalisation, largely relates to the way in which they include institutioning as an active and explicit component. We further explore this argument in three concluding points of discussion.

First, the potential for effecting political change is underscored by defining institutioning in PD and Co-Design processes, not solely as an analytical framework, but as a verb or practice which highlights work that often remains in the back office when participation on the ground is privileged. We explained institutioning as a process of articulation of and reflection on these processes' dependencies on various institutional frames, which can, conversely, directly and/or indirectly lead to changes in a variety of institutional frames. Institutioning thus draws attention to the institutional character of PD 
and Co-Design processes, stressing that: (1) they cannot be understood exclusively as projects on a micro-level, but are dependent on and informed by institutions at meso- and macro-levels; (2) they have the capacity to effect direct and indirect institutional change; (3) their institutional dependencies and potentials are multi-scalar and multi-directional, as is navigation through them; and, (4) although they operate primarily on a micro-level, they generate many direct and indirect effects on meso- and macro-level institutional frames through relations that are consolidative, challenging, and/or formative.

Second, institutioning's expanded recognition of potential political capacity alters our understanding of what participation is. Institutioning involves an articulation and reflection on the ways in which various public and private institutions explicitly or implicitly 'participate' in PD and Co-Design processes and vice versa. Institutioning can thus be seen as participation in an expanded sense: potentially including not only micro-bodies such as persons or groups but also meso-bodies such as local and regional organisations or institutions and macro-bodies such as national and transnational organisations and institutions. In this notion of participation, researchers do not only engage with institutions as externals, but are already a part of institutional framing processes in their capacity as researcher - both as pawns and players. Although this double aspect of PD and Co-Design practices can be deeply problematic in terms of instrumentalisation or tokenism, it can alsotaking into account the discussion on incremental institutional change (Mahoney and Thelen 2009) — offer the potential of reclaiming these practices' transformative heritage. We suggest that the actualisation of this potential is dependent on the way PD and Co-Design processes are able to navigate, situate, and position themselves (as consolidative, challenging, and/or formative) in relation to the range of frames (policy frames, institutional action frames, and meta-cultural frames) shaping the institutions (at micro-, meso-, and macro-levels) which host, supplement, and support them. This returns us to one of our primary implicit arguments: that although the apparent impact of participation processes is on the ground, their extended impact may be greater — although less traceable and harder to substantiate—on a meso- or even macro-level, where they directly and indirectly play a role in the creation of new institutions as well as the reconfiguration of existing ones.

Third, the above reflections on PD and Co-Design in the public realm are addressed in different and complementary ways in the articles of this special issue. The success of PD and commoning processes, as demonstrated by Seravalli, Agger Eriksen, and Hillgren as well as Parker and Schmidt, are highly dependent on how they operate in relation to policy frames and institutional action frames (Schön and Rein 1994). Devos, Kaethler, and De Blust argue 
that the principal challenge is to balance between the critical potential of PD and its instrumentalisation, advancing the concept of 'strategic ambiguity' as a framework for negotiating 'a balance between access, trust, and criticality'. The prototyping of policy and policy frames, as outlined by Kimbell and Bailey, describes a field of operations equally important to PD and Co-Design if they are to have the ambition to move beyond status quo. Markussen argues for a more articulated understanding of 'the social' in social design, addressing differences in the meta-cultural frames of social design, social innovation, and social entrepreneurship which define the ways in which these practices navigate and engage with and within the public realm.

From this discussion on the political capacity of institutioning, we can conclude that institutioning involves a practice of navigating in a structured yet highly porous institutional landscape, through attentiveness to dependencies but also by canalizing synergies and serendipities. It involves a practice of interweaving between — as well as producing — various insides and outsides in participatory processes, by consolidating and challenging existing institutional frames as well as by forming new ones. Institutioning stresses the promise of PD and Co-Design processes being substantial political practices in which researchers, designers, and other actors can play a role in shaping not only our shared public spaces but our shared public institutions. Institutioning could contribute to a heightened understanding of the way PD and Co-Design processes continue to coevolve with historical, geographical, and institutional factors. As outlined by many of the contributions to this special issue, this can enable researchers to be more reflexive and responsive, not only in these contexts, but in the Global South.

\section{References}

Ahrensbacj, Timothy, and Joost Buenderman. 2012. Compendium for the Civic Economy. Amsterdam: Trancity Valiz.

Ampatzidou, Cristina, Matthijs Bouw, Froukje van de Klundert, Michiel de Lange, and Martijn de Waal. 2015. The Hackable City: A Research Manifesto and Design Toolkit. Amsterdam: Amsterdam Creative Industries Publishing. 
Bannon, Liam J., and Pelle Ehn. 2012. "Design: Design Matters in Participatory Design.” In Routledge International Handbook of Participatory Design, edited by Jesper Simonsen and Toni Robertsen, 37-63. New York: Routledge.

Björgvinsson, Erling, Pelle Ehn, and Per Anders Hillgren. 2010. "Participatory Design and 'Democratizing Innovation'.' In Proceedings of the 11th Biennial Participatory Design Conference, 41-50. doi:10.1145/1900441.1900448.

Blomberg, Janet. 1993. "Ethnographic Field Methods and their Relation to Design.” In Participatory Design: Principles and Practices, edited by Doug Schuler and Aki Namioka, 123-127. New Jersey: Lawrence Erlbaum Associates Publishers.

Boudry, Linda, Peter Cabus, Eric Coryn, Filip De Rynck, Chris Kesteloot, and André Loeckx. 2003. De eeuw van de stad: over stadsrepublieken en rastersteden. Brussel: Project Stedenbeleid, Administratie Binnenlandse aangelegenheden.

Castell, Pål. 2016. "Institutional Framing of Citizen Initiatives: A Challenge for Advancing Public Participation in Sweden.” International Planning Studies 21 (4): 305-316.

Christopherson, Susan. 1994. "The Fortress City: Privatized Spaces, Consumer Citizenship." In Post-Fordism: A Reader, edited by Ash Amin, 409-427. New York: John Wiley \& Sons.

Dindler, Cristian, and Ole Sejer Iversen. 2014. "Relational Expertise in Participatory Design.” In Proceedings of the 13th Participatory Design Conference: Research Papers - Volume 1, 41-50. doi:10.1145/2661435.2661452.

DiSalvo, Carl, Andrew Clement, and Volkmar Pipek. 2012. "Participatory Design For, With, and By Communities." In Routledge International Handbook of Participatory Design, edited by Jesper Simonsen and Toni Robertsen, 182-209. New York: Routledge.

Devos, Tim, Michael Kaethler, and Seppe De Blust. 2017. “Ambiguity as Agency: Critical Opportunists in the Neoliberal City." (this issue) 
Graham, Steven, and Simon Marvin. 1994. "More than Ducts and Wires: Post-Fordism, Cities and Utility Networks." In Managing Cities: The New Urban Context, edited by Patsy Healey, Stuart Cameron, Simin Davoudi, Stephen Graham, and Ali Madani-Pour. London: John Wiley \& Sons.

Jenkins, Henry. 2006. Convergence Culture: Where Old and New Media Collide. New York: New York University Press.

Kimbell, Lucy, and Jocelyn Bailey. 2017. "Prototyping and the New Spirit of Policymaking." (this issue)

Kyng, Morten. 2015. "On Creating and Sustaining Alternatives: The Case of Danish Telehealth.” Aarhus Series on Human Centered Computing 1 (1): 12. doi:http://dx.doi.org/10.7146/aahcc.v1i1.21297.

Le Dantec, Christopher, and Carl DiSalvo. 2013. "Infrastructuring and the Formation of Publics in Participatory Design.” Social Studies of Science 43 (2): 241-264.

Lenskjold, Tau Ulv, Sissel Olander, and Joachim Halse. 2015. "Minor Design Activism: Prompting Change from Within.” Design Issues 31 (4): 66-77. doi:10.1162/DESI_a_00352.

Mahoney, James, and Kathleen Thelen. 2009. Explaining Institutional Change: Ambiguity, Agency, and Power. Cambridge: Cambridge University Press.

Mair, Peter. 2013. Ruling the Void: the Hollowing of Western Democracy. London and New York: Verso.

Markussen, Thomas. 2017. “Disentangling 'The Social' in Social Design's Engagement with the Public Realm.” (this issue)

Mouffe, Chantal. 2013. "Institutions as Sites of Agonistic Intervention.” In Institutional Attitudes: Instituting Art in a Flat World, edited by Pascal Gielen, 63-77. Amsterdam: Valiz. 
Mouffe, Chantal. 1993. The Return of the Political. London and New York: Verso.

Parker, Peter, and Staffan Schmidt. 2017. "Enabling Urban Commons.” (this issue)

Rancière, Jacques. 2010. Dissensus: On Politics and Aesthetics. London and New York: Continuum.

Rancière, Jacques. 2004. Aesthetics and Its Discontents. Cambridge: Polity Press.

Schön, Donald A., and Martin Rein. 1994. Frame Reflection: Toward the Resolution of Intractable Policy Controversies. New York: Basic Books.

Seravalli, Anna, Mette Agger Eriksen, and Per-Anders Hillgren. 2017. "Co-Design in CoProduction Processes: Jointly Articulating and Appropriating Infrastructuring and Commoning with Civil Servants." (this issue)

Streeck, Wolfgang, and Kathleen Thelen. 2005. Beyond Continuity: Institutional Change in Advanced Political Economies. New York: Oxford University Press.

Teli, Maurizio. 2015. "Computing and the Common. Hints of a New Utopia in Participatory Design." Aarhus Series on Human Centered Computing 1 (1): 4. doi:http://dx.doi.org/10.7146/aahcc.v1i1.21318. 